\title{
Neuroscience, unconscious processes: Clinical applications
}

\section{Lawrence Greenman}

Veterans Administration New Jersey Health Care System, Lyons, USA

Email: lgreenmanmd@msn.com

Received 7 December 2012; revised 5 January 2013; accepted 12 January 2013

\begin{abstract}
This article reviews selected neuroscience and psychoanalytic writings about respective concepts regarding unconscious processes. Two objectives are pursued. The first is the modification of an apparent dualistic view of the psychoanalytic, dynamic unconscious described by Freud and the implicit, automated unconscious described by neuroscientists into a unified unconscious process concept. Secondly, to examine the functional, structural theory of Freud and to connect it to neuroscience findings via neurodevelopment and the concomitant development of speech and language, an exclusive communicative capacity of the human species. The goal is to illustrate the application of the objectives into clinical settings.
\end{abstract}

Keywords: Genome; Neuroscience; The Unconscious; Structural Theory; Clinical Applications

\section{INTRODUCTION}

The literature of neuroscience and psychology contains a vast amount of findings and information derived from scientific investigations, clinical studies, and theoretical hypotheses which clinicians evaluate and assimilate. Patients present with their unique, integrated physical and psychological pathologies expressed through their behavior and individual personalities. In modern molecular biology and genetics the genome is the entirety of an organism's hereditary information. The constituents of the genome are represented in the receptor mechanisms of the cells of the central nervous system (CNS), autonomic nervous system (ANS), and peripheral nervous system (PNS). The cell membranes of the nervous systems are candidate genes intrinsically involved in the differentiation, development, and functioning of all biological organ systems. Neurons develop and make connections not only within the CNS, ANS, and PNS but within every organ system of the body. The differentiation of organ systems is determined by tissue specific genes in proximity to other specific genes interacting with each other to a greater or lesser degree. The process is guided by subtle intrinsic action potentials of cell membranes in synchronization with functional neural circuits. Edelman [1] states that, "the development of individuals is constrained by genes and inheritance and from early life on is epigenetic. Neurons extend the branching process in many directions generating extensive variability in the connective patterns of neural circuits. Neurons that fire together, wire together in the developing individual which persists throughout each individual's lifetime." Elemental potential for change lies within the genome itself. According to the Encode Project [2], "It is not just the gene but the network that makes the gene dynamic... transcription factors-special genes that can simultaneously activate or silence thousands of genes and are wired together in hierarchal fashion..." Edelman [3] states that, "the brain is an example of a self-organizing system." Groups of neurons function together based on an individual's motor, mental, and trans-organ system activities and are disposed into maps in the brain that connect and overlap. Along with simultaneous input from the neural activity of the sense organs, there occurs a hierarchal synchronization of maps into a, "global mapping" of various maps. Global mapping activity of the brain cortex includes, of course, connections with the emotional centers of the brain, the so-called hedonic centers. The formatting of mental concepts is the product of the brain categorizing its own activities by way of memory processes and perceptions both internal [including fantasy] and external. Damasio [4] described a somatic marker hypothesis which consists of bodily sensations that is in juxtaposition to the brain's capacity to image events. He posits an image space in which disposional memories are reconstituted in recall held in neuron assemblies called, "conversion zones." Conversion zones are hypothesized to represent cortical, and subcortical regional centers of the brain [hedonic centers] involved in the act of perceiving and responding to brain images and external objects. Damasio [5] states, "emotions also effect the modes of operation of numerous brain circuits; the variety of emotional responses is both responsible for profound changes in both the body landscape and the brain landscape.” The collection of 
these changes constitute the substrate for the neural patterns which eventually becomes feelings and emotions. Emotions persistently influence higher level thought processes. Speech and language is the pathway to higher thinking and allows for open ended formation of concepts. It pertains to a capacity for metaphor, symbolism, abstraction, and creativity. Edelman [6] states that, "The fundamental mental triad of higher brain function is composed of perceptual categorization, memory, and learning... it involves continual motor activity and repeated rehearsal in different contexts." Kandel [7] identifies the merger of psychology and neuroscience as cognitive neuroscience. The two subordinates of cognition are learning and memory. He holds the view that, "alteration in gene expression induced by learning indicates that a major consequence of such alteration is the growth of synaptic connections and the changes in patterns of neural connections.” Hyman [8] describes the neurobiology of clinical addictions which he believes might serve as a model for the plasticity of the brain in connection with emotional pleasure factors. His model involves the transcription of ribonucleic acid (RNA) over a period of several months. These patterns develop as well in cadence with the development of speech and language that is central to bring about higher order thinking involving open ended thought processes and distinctive thinking capabilities. The purview of understanding higher level thinking belongs to the realm of psychology and psychoanalysis. I will turn now to my first objective, "the unconscious" a term which seems to imply a selfcontained entity.

\section{THE UNCONSCIOUS PROCESS OF NEURAL CIRCUITS AND NEUROPSYCHOLOGY}

Regina Palley [9] states that, "the bridge between the neuroscience of emotion and psychoanalysis is that both center on unconscious mechanisms. Neuroscience asserts that emotion is processed independently of conscious awareness; not the dynamic unconscious of Freud but in a biographical unconscious governed by the rules and constraints of neural circuits and neuropsychology." She believes that the findings of neuroscience reveals that non-verbal communication between mother and infant, as is illustrated by attachment (mother-infant feedback loop in which mother and infant regulate each other) regulates minds and bodies between individuals. Westin [10] asserts that, "the concept of 'the unconscious' has outlived its usefulness because there are many different kinds of unconscious processes that serve different functions (many of which have neuroanatomical substrates). Cognitive scientists today recognize at least two systems, one conscious (called explicit) and the other unconscious (called implicit). An example of implicit memory is procedural memory of how to ride a bicycle, throw a ball or play a musical instrument. Another kind of implicit memory involves associative memory the formation of associations that guides mental processes and behavior outside of consciousness." Researchers have studied a multitude of unconscious processes which serve many functions, ranging from sensation and perception to memory, decision making, emotion, and motivation. Westin argues that such a large set of processes should not be lumped together and be called, "the unconscious", as if they all do the same thing, serve the same function or operate under the same principles. We should instead speak of unconscious processes. An example of unconscious factors determining behavior is a post-hypnotic suggestion. The posthypnotic subject, at a predetermined signal by the hypnotist, gets up, walks to the sink, pours himself a glass of water and drinks it all outside of his awareness that he was told to do it while in a hypnotic state, It demonstrates how a thought can bring about a complex motor activity. Freud himself believed that slips of the tongue were a simple way to illustrate unconscious mental conflict. My own observation is that nearly everyone becomes an instantaneous, transitory Freudian when exposed to a slip of the tongue that has a sexual connotation. There are different degrees of participation of unconscious processes along with neurodevelopment as each individual experiences mental activity in connection with perceived external events and situations. In my view, neurodevelopment is based on the dynamic genome with candidate genes represented in cell membranes of the nervous systems throughout human functioning. That is, the CNS, ANS, and PNS are expressed in transorgan responses. In basic fight or flight responses mediated through neurotransmitters there is no quibbling about alternative views or interpretations of memories implicit, explicit, hormonal releases (i.e. cortisol), unconscious or conscious mental activity. Networks of neuronal activity are at play with the connecting line being that of epigenetically determined neural membrane responses acting synchronously. Clinically, the syndrome of Post Traumatic Stress Disorder serves as an example of imagery interlaced with different organ systems; somatic symptoms, both motor and autonomic, and with changes in behavior. An acute episode may be triggered by various sensory stimuli such as visual, auditory, olfactory, and others that may have been associated with the experienced trauma. "The neurons that fire together, wire together," as Edelman has stated and can be properly extended throughout life experiences. The neurons that wire together include those circuits linked to emotional, affective centers in the brain. These links are widely believed to be involved with the evolutionary imperatives, so-called instinctual drives related to survival (ag- 
gression) and propagation (sexual) of the human species. Unique for the human species is the development of speech and language in conjunction with social and cultural influences. Unconscious processes are inherent in neurodevelopment in the context of interactions with primary family figures and interpersonal relationships throughout life as individual human dramas unfold. At this point I will take up the second objective of this article which is to connect Freud's Structural Theory with neuroscience.

\section{THE STRUCTURAL THEORY AND NEUROSCIENCE}

Fisher [11] cites Freud who stated, "The poets and philosophers before me discovered the unconscious; what I discovered was the scientific method by which the unconscious mind can be studied." He was referring to the method of free association that is still practiced today. Psychoanalysis is not only a therapeutic modality but remains a productive research modality that has generated the most comprehensive understanding of human emotions, thinking, and behavior, neuroscience notwithstanding. In his hallmark book, The Interpretation of Dreams, Freud worked out many of the mental mechanisms involved in dream work such as displacement, condensation of mental images, and considerations of the representativeness of mental images. He distinguished between primary process thinking and secondary process thinking which has relevance in clinical psychiatry today. Arieti [11] refers to von Domarus who described primary process thinking in which a schizophrenic may form a delusion based on identification of predicates to form a conclusion. For example, Subject A, who has white hair and a white mustache, might think, "I am a man with white hair and mustache. Albert Schweizer (Subject B) has white hair and a white mustache. Therefore, I am Albert Schweizer.” Logical or Aristotelian secondary process cognition, in contrast, rejects that type of identification because, logically, if Subject A and Subject B are different, they cannot be the same. The law of identity says that A is always A, never B. At the other end of the thinking spectrum, Kandel $[12,13]$ states, "Because primary process is freer and hyper associative, it is thought to facilitate the emergence of creativity that promotes new combinations and permutation of ideasthe equivalent of an Aha! moment where the full focus of secondary processes thinking is required for the working through, the elaboration of creative insight... like much of our cognitive and affective life, even our decision making is partially unconscious suggests that unconscious mental processes are necessary for creative thinking as well."

Neurodevelopment is grounded in the dynamic geno- me expressed in motor and glandular outlets. The lines of connection are candidate genes in membranes of neurons branching out in trans-organ coordination. Evolutionary imperatives of survival (aggressive instinct) and propagation of species (sexual instinct) develop in conjunction with motor, sensory, and mental interplay, including phantasy. The long period of infantile dependency on parents/caregivers necessarily incorporates those figures in the neuropsychological development of individuals. Freud first conceived of a topical model of the mind: unconscious, pre-conscious, and conscious. When it became apparent that mental defense mechanisms, monitored by a pleasure-unpleasure continuum, were themselves partially unconscious, he abandoned the topical theory in favor of the structural theory. The structural theory is a functional entity comprised of Id, Ego, and Superego working in unison each containing varying degrees of conscious and unconscious dimensions. Brenner [14] emphasized the monitoring of sexual and aggressive drive derivatives according to the pleasure-unpleasure spectrum. He maintains that the mind is in continuous intrinsic conflict and attempts to resolve conflicts by compromise formation in thought and somatic action. He argues that each thought, perception, mental representation has unconscious and conscious participation of Id, Ego, and Superego in varying proportions. I would add, in a neurophysiological vein, that all thoughts and actions are grounded in parallel neurological networks via intercellular and trans-organ communication. The connecting mechanisms are propagated by the candidate gene receptors on nerve cell membranes of the CNS, ANS, and PNS. Neural networks underlie cognition, perception, memories and phantasies with obligatory simultaneous activity of the neural circuitry of emotional centers located in the midbrain particularly the thalamus, cingulate gyrus, and amygdale nucleus with their neural projections to the cerebral cortex. According to the structural theory, unconscious and conscious processes are merged in varying proportions which determine the outcome of thoughts, feelings, emotions and actions. I will leave it to those who disagree to explain why unconscious processes alone should be exempt from dynamic neuropsychological processes. Now that my two objectives have been set forth I will turn to the goal of illustrating the application of the discussed objectives to the clinical venue.

\section{CLINICAL MANIFESTATIONS OF UNCONSCIOUS PROCESSES}

In the current dominance of biological psychiatry expressed in psychopharmacology, the clinical psychiatrist routinely makes medication appointments which last conventionally for 20 - 30 minutes. It is instructive to 
trace back to the model used in the development of neuroleptic agents. Snyder [15] states, "Both amphetamines and apomorphines produce in rats stereotyped sniffing, licking and gnawing. These drugs produce fighting among male rats and enhance rope climbing behavior in mice. All of these effects are antagonized by neuroleptics in proportion to their dopamine blocking properties." Pharmaceutical companies then do toxicology studies, next pre-clinical trials, and then clinical trials to determine efficacy before submitting to the Federal Drug Administration for approval. It's hard to reach an understanding of human behavior and higher level thinking derived from a rat model. Perusal in the Physician's Desk Reference of the mechanism of action of neuroleptic medications show that they are essentially unknown in spite of all the technical investigations conducted by neuroscientists. The range of side effects, however, is well known and reflects a trans-organ response. In general, the specificity of the nervous system and other biological findings do not provide a comprehensive understanding of human behavior and higher level thinking. Clark [16] stated that Einstein was asked, "Do you believe that absolutely everything can be expressed scientifically", "Yes," he replied, it would be possible, but it would make no sense. "It would be description without meaning —as if you described a Beethoven symphony as a variation of wave pressure."

Freud [17] stated in regard to his theory of dreams, "but if you ask me how much of dream interpretation has been accepted by outsiders - by the many psychiatrists and therapists who warm their pot of soup at our fire (incidentally without being very grateful for our hospitality)... The reply finds little cause for satisfaction.” He might say the same for his psychoanalytic findings today. Nonetheless, they turn up in modern clinical practice albeit indirectly. I have discussed above how the structural theory relates to neurobiological facts. Along the way of its development psychology and biological psychiatry has spun off a considerable amount of psychobabble and analogous bio-babble. Over the past half-century behavior therapy and cognitive therapy have been widespread. It is risky, however, to ignore the origin of things so these latter treatment techniques have undergone necessary modifications. A combination technique known as cognitive behavior therapy (CBT) has emerged followed by dialectic-behavior therapy (DBT) whereby the, "talking cure" is brought in. Next appeared transference focused psychotherapy (TFP) which necessarily must involve countertransference phenomenon as well. Mentalization based therapy (MBT) has a more psychodynamic approach dealing with emotions and feelings. Schema focused therapy (SFT) seems to be a composite of several therapies. The foregoing therapies have obvious roots in the psychoanalytic literature. In the course of clinical treatment the clinician frequently encounters the psychoanalytic concept of "resistance" to treatment manifested by lack of adherence to medication regimens, treatment protocols, a pattern of late or missed appointments, breach of so-called contracts for treatment, etc. Dependency/independency issues of control may interfere with proscribed treatment. Every psychiatric and psychosocial assessment of the presenting illness is traced back to the patient's individual's personal history of earlier life experiences. Attention is paid to the individual's interpersonal relationships, traumatic events, and the influence of early family caretakers. Gabbard [18] states, "A basic premise of psychodynamic thinking is that internal object relations etched in neural networks from early childhood development tend to repeat themselves again and again in adult relationships." The fundamental psychoanalytic discovery that conflicts of the past continue to influence present behavior and the capacity to resolve mental conflicts by verbalizing them is extant.

\section{CONCLUSION}

In a Darwinian sense, the facts and findings of neuroscience and the concepts of psychoanalysis will be validated by their durability and serviceability. Both will survive and will be determining factors in humankind's vicissitudinous pathway into the future. In addition to treating acute clinical presentations clinicians are faced with the need for chronic maintenance therapy and management. This will inevitably involve the personality of the patients/clients that requires an integrated biological and psychological foundation. An operational familiarity with psychoanalytic premises, tenets, and postulates would, therefore, be of benefit to providers in the clinical encounter.

\section{ACKNOWLEDGEMENTS}

The author would like to thank Robert and Jax Kovacs for their assistance in the preparation of the manuscript. I am grateful to Leon Hoffman, M.D, for his thoughtful suggestions which are reflected in the content of the article.

\section{REFERENCES}

[1] Edelman, G.M. and Tononi, G. (2000) A universe of consciousness: How matter becomes imagination. Basic Books, New York.

[2] Yale University (2012) Yale team finds order amidst the chaos within the human genome. Science Daily. http://news.yale.edu/2012/09/05/yale-team-finds-order-a midst-chaos-within-human-genome-mom-and-dad-s-cont ributions-counte

[3] Edelman, G.M. (1992) Bright, air, brilliant fire: On the 
matter of the mind. Basic Books, New York.

[4] Damasio, A.R. (1994) Descartes' error: Emotion, reason, and the human brain. GP Putnam, New York.

[5] Damasio, A.R. (1999) The feeling of what happens: Body and emotions and the making of consciousness. Harcourt Brace, New York.

[6] Edelman, G.M. (1992) Bright air, brilliant fire: On the matter of the mind. Basic Books, New York.

[7] Kandel, E. R. (2005) Psychiatry, psychoanalysis, and the new biology of mind. American Psychiatric Publishing Inc., Washington DC.

[8] Hyman, S.E and Nestler, E.J. (1996) Initiation and adaption: A paradigm for understanding psychotropic drug reaction. American Journal of Psychiatry, 153, 151-162.

[9] Palley, R. (1998) Emotional processing: The mind-body relationship. International Journal of Psycho-Analysis, 79, 349-362

[10] Westin, D. (1999) The scientific status of unconscious processes: Is Freud really dead? Journal of the American Psychoanalytic association, 47, 1061-1106. doi:10.1177/000306519904700404
[11] Fisher, C. (1974) Freud's metapsychology. Psychoanalytic Quarterly, 11, 607-608.

[12] Arieti, S. (1974) Interpretation of schizophrenia. Basic Books Inc., New York.

[13] Kandel, E.R. (2012) The Age of insight. Random House, Inc., New York.

[14] Brenner, C. (2002) Conflict, compromise formation, and the structural theory. Psychoanalytic Q, 71, 407-408.

[15] Snyder, S. and Largent, B.L. (1989) Receptor mechanisms in antipsychotic drug action: Focus on sigma receptors. The Journal of Neuropsychiatry and Clinical Neurosciences, 1, 7-15.

[16] Clark, R.N. (1972) Einstein: The life and times. Avon Books, New York, 243.

[17] Freud, S. (1957) Revision of the theory of dreams. In: Strachy, J., Ed., The Standard Edition of the Complete Works of Sigmund Freud, The Hogarth Press, London, 8.

[18] Kassaw, K. and Gabbard, G.O. (2002) Creating a psychodynamic formulation from a clinical evaluation. American Journal of Psychiatry, 5, 721-726. doi:10.1176/appi.ajp.159.5.721 